\title{
Research advance of the model of activated sludge process to wastewater treatment
}

\author{
Zhou Jia ${ }^{1, a}$, Ma Limin ${ }^{1, b^{*}}$ and Song Houran ${ }^{1, c}$ \\ ${ }^{1}$ Tongji University, \\ State Key Laboratory of Pollution Control and Resource Reuse Study, \\ College of Environmental Science and Engineering, \\ Shanghai, China, 200092 \\ a853089302@qq.com, 'Imma@tongji.edu.cn, csonghouran@hotmail.com
}

Keywords: activated sludge process; model; ASM

\begin{abstract}
Activated sludge process model is a powerful tool. Wastewater treatment plant can monitoring and control the capacity and efficiency of sewage treatment accurately through activated sludge process model. This paper demonstrates the development and improvement of the activated sludge process model in detail. Thus it combs the whole process of activated sludge process model and establishes the solid foundation for the further research and improvement of activated sludge process model.
\end{abstract}

\section{Introduction}

In China, the technology of sewage treatment is mainly the activated sludge process at present. It is currently the widely used all over the world. It is a kind of biological treatment technology. Activated sludge process is a technology that simulates the process of water self-purification, it mainly uses microbial life activities in the sludge to degrade the pollutants in wastewater. Sewage treatment process of activated sludge process is a strong coupling dynamic system which has the multiple input and output. It has many characteristics, such as the highly nonlinear, time-varying and time-delay. These characteristics make difficult for accurately monitoring and control of sewage treatment process.

\section{The development course of activated sludge process model}

Beginning from 1912, activated sludge process has been used for the sewage treatment. It mainly uses microbial life activities in the sludge to degrade and transform the pollutants in wastewater. The earliest relevant mathematical model should dates back to the microbiology research [1]. At 1913, Michaelis and Menten do many kinetics experiments to research on the relationship of the pure enzyme degrade the pure substrate, and they finally present Michaelis - Menten equation. This equation expresses the relationship between the substrate concentration and the enzymatic reaction velocity. Because all the biochemical reactions are finished by the action of enzymes, Michaelis - Menten equation can indirectly shows that the relationship between the speed of microbial degradation and substrate concentration, thus it is widely used in wastewater treatment engineering.

In 1942, Monod [2] proposes the Monod equation that is based on the Michaelis - Menten formula. He mainly points out that it has the relationship among the growth rate of microbes, microbial concentration and some restrictive substrate concentration [3]. In the late 1950s, Eckenfelder, Mckinney, Lawrence and McCarty et al. establish the representative Eckenfelder, Mckinney and Lawrence McCarty, traditional static model of activated sludge system. It is based on the Monod equation, is combined with the reactor theory of the chemical field and the microbiological biochemistry theory, shows the relationship among the substrate degradation, the microbial growth and the parameters by the mathematical model. 
In the 1980s, J.F.Andrews from American proposes the J.F.Andrews dynamic model. Then, the Water Research Center (WRC) from UK proposes the WRc dynamic model. They use the different mechanisms to explain some phenomenon that the traditional static model cannot explain, but there are still two major issues for this kind of model: (1) the endogenous respiration theory is used to describe the microbial attenuation process in this kind of model, but it does not consider its recycling problem of metabolic residue; (2) this kind of model only describes the degradation process of the carbon-containing organic compounds in wastewater, can't simulate and predict the degradation of nitrogen and phosphorus.

In order to solve these two problems, in 1986, the International Association of Water quality (IAWQ) and the International Water Supply Association (IWSA) get combined into the International Water Association (IWA) and launched the activated sludge model NO.1 (ASM1). ASM1 is considered a milestone in the development course of the activated sludge process model, contains the process of the microbial nitrification reaction, the microbial denitrification reaction and the microbial carbonization reaction [4]. ASM1 describes eight reaction processes of the sewage in aerobic and anoxic conditions, such as the organic compounds hydrolysis, the organic compounds degradation, the microbial growth and attenuation et al., and it divides the substrates into 13 kinds of components, contains 19 parameters (14 dynamics parameters, 5 stoichiometric parameters) due to the considerations of biological solubility and degradability. As a tool that simulates the activated sludge system efficiently, ASM1 has been widely used in the Europe and the United States since it is launched. But its popularization and application have some limitations, because it does not contain the phosphorus removal.

In 1995, the activated sludge model NO.2 (ASM2) is launched by IWA. As the enhanced version of ASM1, ASM2 adds the biological and chemical phosphorus removal process, the reaction process of the anaerobic hydrolysis and the reaction process of fermentation. ASM2 altogether contains 19 reaction processes and 64 parameters (42 dynamics parameters, 22 stoichiometric parameters) [5]. Because of the complexity of the ASM2 and the uncertainty of phosphorus removal process, ASM2 is not widely applied, compared with ASM1.

In 1999, the activated sludge model NO.3 (ASM3) is launched by IWA. In the ASM3, the microbial attenuation process adopt the theory of the endogenous respiration. Its emphasis turns the hydrolysis to the organic compounds of the intracellular storage, and it underlines the activity process within the cell [6]. ASM3 altogether contains 13 components, 12 reaction processes and 27 parameters. Although the ASM3 overcome the main shortcoming of ASM1, because the ASM3' time is short, its application value and the accuracy of the model are still needed the further evaluation, modification and improvement, and it is also validated through a lot of tests and operating data.

\section{The improvement of activated sludge process model}

Currently, ASM1 has gained wide acceptance and application in academic and engineering fields. According to Hauduc etc., there is a survey about which model is the most commonly used model of the wastewater biological treatment process in worldwide, $57 \%$ of the feedback data show that they are using ASM1 [7]. ASM1 has been successfully applied to simulate a variety of nitrogen and carbon removal process of the wastewater biological treatment process, and there are dozens of years of successful operating experience, and it has been widely applied to the traditional activated sludge process $[8,9]$, the oxidation ditch technology $[10,11]$, the sequencing batch activated sludge process [12], the membrane bioreactor [13], moving bed biofilm reactor [14], etc. Such messages often appear in various scholarly journals and operating reports. It fully explains that ASM1 has been widely acknowledged.

In recent years, because ASM1 has a widely successful application and the problems appear in its application, there are a lot of the further expanded and improved study about ASM1. For example, in view of the problems that ASM1 can't describe well the sewage sedimentation after the aeration process, the International Water Association (IWA) and the Cooperation Organization Science and Technology of European Union (COST) jointly build a base platform named Benchmark Simulation Model No. 1 (BSM1) [15]. BSM1 adopts the dual index sedimentation rate model of Takacs et al. to supplement the 
dynamic characteristic of the sedimentation tank in the wastewater treatment process, and it sets up a simple control strategy. It is convenient to model and automatically control for researchers all around the world in the operating process of activated sludge wastewater treatment plant. Maryns and Bauwens modify ASM1, and they use it to simulate the river environment in the area of Flanders, Belgium. This study shows that river model can be combined with the sewage treatment plant model to realize the integrated management of water quality [16]. According to the principle of charge balance, Magri etc. add the related equation to reflect the actual changes of $\mathrm{pH}$ in ASM1. It is used to simulate the SHARON process [17]. Combined ASM1 model with floc model, Wang, etc successfully simulate the operation situation of sewage treatment plant when the aeration tank has the simultaneous nitrification and denitrification under condition of low concentration of dissolved oxygen [18].

B\&D model is actually based on ASM1, makes up the phosphorus removal process that the ASM1 don't express, is combined with the theory about the kinetics of phosphorus accumulating microorganisms, amends the behavior that phosphorus accumulating microorganisms absorb phosphorus $(\mathrm{P})$ in wastewater and the process of removing nitrogen by the denitrification under the anoxic conditions, and considers the loss of the corresponding COD [19], allows that this model expresses a more comprehensive statement of the nutrient removal mechanism, expands the application of this model. At the same time, Barker and Dold think only part of phosphorus accumulating microorganisms can use the nitrogen oxide ions as the electron acceptor to degrade polyhydroxybutyrate under the anoxic conditions [19]. For convenience of build the model, Barker and Dold only set the different conditions of the dynamics forms for the same kind of PAOs flora, namely compared with aerobic conditions, the phosphorus removal ability of the anoxic conditions need to be multiplied by the proportional coefficient that is less than 1. Moreover, Barker and Dold also think the precondition that the phosphorus accumulating microorganisms have an ability of the denitrification is only that the ammonia concentration and the phosphate concentration are smaller in the model [19].

$\mathrm{B} \& \mathrm{D}$ model also considered the loss of the corresponding COD in the process of denitrification and phosphorus removal. They think the loss of the corresponding COD mainly comes from the volatile organic acids. These volatile organic acids mainly include the transformation behavior of the easily degradable organic, the hydrolytic behavior of the hardly degradable organic and the volatile organic acids that phosphorus accumulating microorganisms absorb in the fermentation process.

TUDP model is a new model, which is a combination of the metabolism model by Murnleitner et al. and the ASM1 model [20-22]. This combination is not only considered to describe the autotrophic and heterotrophic biochemical reactions of ASM1 model in detail, but it adds the denitrification of phosphorus accumulating microorganisms. All these are used to improve and perfect the ASM1 model. Unlike ASM2 or ASM2d model, TUDP model fully considers three ways of phosphorus accumulating microorganisms metabolism, namely the anaerobic, anoxic and anaerobic-aerobic conditions, makes more clear all the transformation approach of the organic storage (glycogen and PHA). TUDP model is proved validated by many researchers. These researchers simulate the different test conditions of the sequencing batch reactor which contains a rich phosphorus accumulating microorganisms. These test conditions include the different hydraulic retention time [23], the different run length of anoxia and aerobic periods [24] and the different electron acceptor [22], et al.

In addition, on the basis of the simulation of the tranditional dephosphorization process, phosphorus transformation approach of TUDP model is still concentrated in absorbing the ATP and phosphate from the degradation of the substrate. In the model, under the premise of the dissolved oxygen and the nitrate ions as the electron acceptor, each unit NADH2 use it to create the ATP, and the coefficients were separately 1.8 and 0.9 . About the absorption of phosphorus, the phosphorus absorption coefficients of oxidation of every unit NADH2 of were separately 7.0 (aerobic) and 3.5 (anoxia) [25].

In addition to the main model, the UCT model [26], the ASM3 + BioP model [27] also has a certain influence in sewage treatment model research field. 


\section{Summary}

The relevant mechanism of activated sludge in the wastewater treatment process is not yet completely clear. The exploration of the unknown is always attracting a large number of researchers. With the further research of the microbial relevant reaction kinetics, I believe there will be a lot of sewage treatment process mechanism model, and then it continues to improve and perfect the model of the activated sludge process.

\section{Acknowledgment}

This work was financially supported by the National High Technology Research and Development Program (“863” Program) of China (2012AA063608).

\section{References}

[1] Henze, M. A general model for bingle-sludge wastewater treatment systems, Water Research., vol. 21, 1987, pp. 505-515.

[2] Lu Peili, Zhang Daijun, Liu Ying. Research progress and prospect of activated sludge process dynamics model, Journal of chongqing university, vol. 25, 2002, pp. 20-23.

[3] Eckenfedler W. W., Connor D. J.. Biological waste treatment, 1st ed., vol. 2. New York: Pergamon Press, 1961, pp. 81-90.

[4] Henze M, Grady C. P, Gujer W, et al., Activated sludge model No.1 London, England: International Association on Water Pollution Research and Control Scientific and Technical Reports, 1986.

[5] Henze M, Gujer W, Mino T, et al., Activated Sludge Model No.2. London, England: International Association on Water Pollution Research and Control Scientific and Technical Reports, 1995

[6] Gujer W, Henze M, Mino T, Loosdrecht M. V, Activated sludge model No.3, Water Science \& Technology, vol. 39, 1999, pp. 183-193.

[7] Hauduc H, Gillot S, Rieger L, Activated sludge modelling in practice; an international survey, Water Science and Technology, vol. 60, 2009, pp. 1943-1951.

[8] Lesouef A, Payraudeau M, Rogalla F, Optimizing nitrogen removal reactor configurations by on-site calibration of the iawprc activated-sludge model, Water Science and Technology, vol. 25, 1992, pp. 105-123.

[9] Fall C, Loaiza-Navia J, Esparza-Soto M, Full activated sludge model no.1 calibration experience at a medium-size WWTP in Mexico, Water Science and Technology, vol. 60, 2009, pp. 3069-3082.

[10] Stamou A, Katsiri A, Mantziaras I, Modelling of an alternating oxidation ditch system, Water Science and Technology, vol. 39, 1999, pp. 169-176.

[11] Lesage N, Sperandio M, Lafforgue C, Calibration and application of a 1-D model for oxidation ditches, Chemical Engineering Research \& Design, vol. 81, 2003, pp. 1259-1264.

[12] Coelho M, Russo C, Araujo O, Optimization of a sequencing batch reactor for biological nitrogen removal, Water Research, vol. 34, 2000, pp. 2809-2817.

[13] Jiang T, Liu X, Kennedy M. D, Calibrating a side-stream membrane bioreactor using Activated Sludge Model No.1, Water Science and Technology, vol. 52, 2005, pp. 359-367.

[14] Plattes M, Henry E, Schosseler P. M., Modelling and dynamic simulation of a moving bed bioreactor for the treatment of municipal wastewater, Biochemical Engineering Journal, vol. 32, 2006, pp. 61-68. 
[15] J. Alex, L. Benedetti, J. Copp, et al. Benchmark Simulation Model No. 1 (BSM1). Prepared by the IWA Taskgroup on Benchmarking of Control Strategies for WWTPs, 2008

[16] Maryns F,Bauwens W., The application of the activated sludge model no. 1 to a river environment, Water Science and Technology, vol. 36, 1997, pp. 201-208.

[17] Magri A, Corominas L, Lopez H, A model for the simulation of the SHARON process: $\mathrm{pH}$ as a key factor, Environmental Technology, vol. 28, 2007, pp. 255-265.

[18] Wang C, Zeng Y Z, Lou J, Dynamic simulation of a WWTP operated at low dissolved oxygen condition by integrating activated sludge model and a floe model, Biochemical Engineering Journal, vol. 33, 2007, pp. 217-227.

[19] Barker P. S., Dold P. L., General model for biological nutrient removal activated-sludge systems: model presentation, Water Environment Research, vol. 69, 1997, pp. 969-984.

[20] Brdjanovic D, Van Loosdrecht M, Versteeg P, Modeling COD, N and P removal in a full-scale wwtp Haarlem Waarderpolder, Water Research, vol. 34, 2000, pp. 846-858.

[21] Van Veldhuizen H. M., Van Loosdrecht M., Brandse F. A., Model based evaluation of plant improvement strategies for biological nutrient removal, Water Science and Technology, vol. 39, 1999, pp. 45-53.

[22] Murnleitner E., Kuba T., Van Loosdrecht M., An integrated metabolic model for the aerobic and denitrifying biological phosphorus removal, Biotechnology and Bioengineering, vol. 54, 1997, pp. 434-450.

[23] Smolders G., Klop J. M., Van Loosdrecht M., A metabolic model of the biological phosphorus removal process .1. Effect of the sludge retention time, Biotechnology and Bioengineering, vol. 48, 1995, pp. 222-233.

[24] Kuba T., Van Loosdrecht M., Murnleitner E., Kinetics and stoichiometry in the biological phosphorus removal process with short cycle times, Water Research, vol. 31, 1997, pp. 918-928.

[25] Thesen A., Some notes on systems models and modeling, International Journal of Systems, vol. 5, 1974, pp. 145-152.

[26] Hu Z. R., Wentzel M. C., Ekama G. A., Modelling biological nutrient removal activated sludge systems - a review, Water Research, vol 37, 2003, pp. 3430-3444.

[27] Rieger L, Koch G, Kuhni M, The EAWAG Bio-P module for activated sludge model No.3, Water Research, vol. 35, 2001, pp. 3887-3903. 